\title{
Sea Level controls on Agulhas Leakage Salinity and the Atlantic Overturning Circulation
}

\section{Sophie Nuber ( $\nabla$ sophie.nuber@hotmail.de )}

National Taiwan University

\section{James Rae}

University of St Andrews https://orcid.org/0000-0003-3904-2526

\section{Morten Andersen}

School of Earth and Ocean Sciences, Cardiff University

\section{Xu Zhang}

State Key Laboratory of Tibetan Plateau Earth System, Resources and Environment (TPESRE), Institute of Tibetan Plateau Research, Chinese Academy of Sciences https://orcid.org/0000-0003-1833-9689

\section{Bas de Boer}

Vrije Universiteit Amsterdam

Matthew Dumont

University of St Andrews

\section{Yuchen Sun}

https://orcid.org/0000-0002-2449-8718

\section{Huw Mithan}

National Taiwan University

lan Hall

School of Earth and Ocean Sciences Sciences https://orcid.org/0000-0001-6960-1419

\section{Stephen Barker}

Cardiff University

\section{Physical Sciences - Article}

Keywords: Agulhas leakage salinity, Atlantic overturning circulation, Indian Ocean

Posted Date: November 5th, 2021

DOl: https://doi.org/10.21203/rs.3.rs-1038170/v1

License: (c) (i) This work is licensed under a Creative Commons Attribution 4.0 International License. Read Full License 


\section{Abstract}

The Indian Ocean has been proposed as an important source of salt for North Atlantic deep-water convection sites, via the Agulhas Leakage, and may thus drive changes in the ocean's overturning circulation. However, while past changes in Agulhas leakage volume have been explored, little is known about this water's salt content, representing a major gap in our understanding of Agulhas salinity supply. Here, we present new planktonic foraminiferal Mg/Ca-derived sea surface temperatures (SST) and stable isotope-derived salinity reconstructions for the last 1.2Ma from the western Indian Ocean source waters of the Agulhas Leakage to investigate glacial-interglacial changes in surface water properties. We find that SST and relative salinity both increase during glaciation, leading to high salinity and SST during glacial maxima. We show that the onset of surface salinification and warming in the Indian Ocean occurs during a phase of rapid land-bridge exposure in the Indonesian archipelago induced by sea level lowering. We link these findings to new global climate model results which show that the export of salt from the Indian Ocean via the Agulhas Leakage can directly impact the deglacial Atlantic meridional overturning circulation and therefore global climate.

\section{Main Text}

The surface salinity distribution in the modern Indian Ocean differs from the distribution patterns seen in the Atlantic and Pacific Oceans at comparable latitudes (Figure 1). Tropical and subtropical Atlantic and Pacific surface waters are characterised by their enhanced warmth and salinity. This is due to their recirculation in subtropical gyres under high net-evaporation. The Indian Ocean is largely located in the tropics and sub-tropics. Therefore, one would expect the development of a warm and salty Indian Ocean subtropical gyre with comparable surface salinities. However, this is not the case. Modern Indian Ocean surface conditions are notably fresher than comparable latitudes in the Atlantic and Pacific. This is due to the inflow of monsoon-derived and Pacific-origin low salinity surface and thermocline waters from the Indonesian Throughflow (ITF) (Figure 1). Inflow occurs via the Timor, Lombok, and Ombai Straits (Sprintall et al., 2009), as well as the Bay of Bengal (Sengupta et al., 2006), and is transported across the tropical Indian Ocean via the South Equatorial Current (SEC) (Talley \& Sprintall, 2005; Sengupta et al., 2006; Gordon et al., 1997). Surface water salinity does increase within the subtropical western Indian Ocean (Talley \& Sprintall, 2005), but the salt is then partially exported through an active Agulhas Leakage (Durgadoo et al., 2017). The addition of Indian Ocean salinity to Atlantic surface waters via the Agulhas Leakage has been proposed as a mechanism to influence global ocean circulation by enhancing the density potential at North Atlantic deep-water convection sites (Beal et al., 2011; Biastoch et al., 2009). It is therefore possible that changes in Indian Ocean surface salinity could directly impact global ocean circulation.

Here, we present coupled SST (from Mg/Ca in the planktonic foraminifer Globigerinoides ruber) and relative salinity reconstructions (see Methods 1) from western Indian Ocean IODP Site U1476 located in the northern entrance of the Mozambique Channel ( $\left.15^{\circ} 49.25^{\prime} \mathrm{S} ; 41^{\circ} 46.12^{\prime} \mathrm{E} ; 2166 \mathrm{~m}\right)$. This site is strongly influenced by the westward flowing SEC (Durgadoo et al., 2017), and thus tracks the hydrographic 
conditions of the western Indian Ocean source waters that feed the Agulhas leakage. Our 1.2 million year (Ma)-long record provides the first evidence for changes in tropical western Indian Ocean hydrography beyond the glacial maximum (LGM). We examine the controls and impacts of these changes to assess the role of Agulhas Leakage salt content in the global overturning circulation and climate.

Our reconstructions show that western Indian Ocean surface salinity and temperature structures were significantly different from modern during Pleistocene glacial stages. Figure 2 shows that western SEC temperature initially cools during glacial inception from its interglacial high. However during the middle and latter phases of glacial cycles, this cooling trend reverses and surface waters begin to warm. In the absence of other influences, this warming would be expected to cause a decrease in planktic $\delta^{18} 0$. However, we find planktic $\delta^{18} \mathrm{O}$ continues to increase, suggesting an increase in $\delta^{18} \mathrm{O}_{\mathrm{sw}}$ and hence surface salinity. Global growth in ice volume can only account for $50 \%$ of the glacial-interglacial difference in $\delta^{18} \mathrm{O}_{\mathrm{sw}}$ across the last 1.2Ma (see supplementary Figure S1). As such, our data indicate a regional increase in sea surface salinity (as well as temperature) during glacial periods. Correcting for the influence of changes in global ice volume (see Methods), our ice volume-corrected $\delta^{18} \mathrm{O}_{\mathrm{sw}}$ and SST data show average increases in $\delta^{18} \mathrm{O}_{\text {sw-ivc }}$ and SST of $0.91 \%$ o $( \pm 0.1 \%$ o $)$ and $4.4^{\circ} \mathrm{C}\left( \pm 0.8^{\circ} \mathrm{C}\right)$, respectively across 16 glacial cycles (Figure 2b, c). Glacial salinification occurs in 15 out of 16 glacial cycles, with the midpoint of the glacial increase in $\delta^{18} \mathrm{O}_{\text {sw-ivc }}$ occurring on average $\sim 15 \mathrm{kyr}$ prior to the glacial termination in $\delta^{18} \mathrm{O}_{\text {benthic }}$ (Figure 2c, Methods 1 ). To examine the regional consistency of this feature, we stacked SST, $\delta^{18} \mathrm{O}_{\text {SW-ivc, }}$ and $\delta^{18} \mathrm{O}_{\text {benthic }}$ records across the Indian Ocean (Figures $1 \& 3$ ) by resampling each record, and averaging the resulting records using a Gaussian smooth (Methods 2). The resulting Indian Ocean stacks show the same patterns of salinification and warming during intensification of glacial conditions (Figure 3e-d), suggesting this is an Indian Ocean-wide phenomenon, particularly along the SEC and the Agulhas System. The change in water mass properties does not apply to Indian Ocean water source regions, such as the South China Sea or the western Pacific Ocean (Figure S2, Methods 3). It is therefore likely to be connected to the intrinsic dynamics of the Indian Ocean. Furthermore, we find that each Indian Ocean salinification event throughout the last 1.2Ma in the $\delta^{18} \mathrm{O}_{\text {sw-ivc }}$-stack is induced when Relative Sea Level (RSL) in the Indonesian archipelago is around $-50 \mathrm{~m}(+/-35 \mathrm{~m})$ (Figure $3 e, \mathrm{f}$ ). Repeating the analysis using $\mathrm{U} 1476 \delta^{18} \mathrm{O}_{\text {sw-ivc }}$ alone yields the same RSL threshold of $-50 \mathrm{~m}(+/-32 \mathrm{~m})$ (Figure S3). This suggests a systematic link between sea level lowering and the Indian Ocean glacial salinification process.

The Indonesian archipelago has been previously highlighted as an area of major land surface reorganisation as a result of changing sea levels (e.g. Petrick et al., 2019). To characterise changes in the sea-land surface distribution as a result of RSL variability, we ran a coupled RSL-topography model ANICE-SELEN (de Boer et al., 2014a) using the van der Lubbe et al. (2021) $\delta^{18} O_{\text {benthic }}$ record from U1476 (see Methods 5). The model output gives spatial information on sea level height changes through time and allows us to assess the timing of land exposure and flooding due to sea level dynamics. Our model results show that the greatest changes in sea-to-land surface area across the Indonesian archipelago 
occur when RSL is between $-2 m$ to $-8 m$, and $-45 m$ to $-55 m$ (Figure $S 4$ ). The shallower of these intervals appears to be linked to the initial exposure of shallow marine geomorphological landforms, such as shallow submarine island channels, estuaries, terraces, shore platforms, sand banks, and coral reefs. Its impact on regional circulation and Indian Ocean surface salinity is therefore small. The deeper interval is directly linked to the abrupt exposure of the Java Straits and North Australian continental shelves. This resurfacing of land in the Indonesian Archipelago will have important implications for the outflow dynamics of the ITF. Indeed, we find a close correspondence between RSL and ITF outflow strength, as reconstructed from $\delta^{13} \mathrm{C}_{\text {benthic }}$ in the Lombok Strait (Holbourn et al. 2011) (Figure 3g, h). This suggests that lowering global sea levels causes a reduction in the ITF outflow due to abrupt land surfacing in the Indonesian Archipelago. The Java Straits and North Australian shelves have both been previously hypothesised to influence regional circulation and surface water hydrography. The exposure of North Australian shelves may reduce the outflow profile area, and therefore the outflow volume of the ITF (Petrick et al., 2019; Holbourn et al., 2011; Gordon et al., 2003). Additionally, the closure of the Java Straits likely inhibits the inflow of surface freshwater lenses from the SCS which, under normal conditions, appear to force a fresh and cool thermocline driven ITF (Holbourn et al., 2011; Sarr et al., 2019). The absence of such lenses therefore triggers stronger surface outflow causing the ITF to be warmer and saltier (Holbourn et al., 2011). As such, the salinity and temperature increase we observe in the tropical and subtropical Indian Ocean is likely linked to a reduction in freshwater entering the Indian Ocean driven by a combination of smaller, saltier volumes of ITF water.

As another major Indian Ocean gateway, changes in the Agulhas Leakage (AL) also have the potential to influence surface hydrography. AL volume reconstructions show that the AL was reduced during glacials within the last 500kyr (Figure 3i) (Peeters et al., 2004; Caley et al., 2012). This has been explained by northward shifts of the subtropical front, coupled to changes in Southern Ocean dynamics, which diminish the outflow space for warm and salty waters between the subtropical front and the African continent (Bard \& Rickaby, 2009). It is likely that the closure of the AL could enhance the salinification process by reducing the outflow of saline waters into the Atlantic and promoting recirculation under net evaporative conditions. Indeed, published records suggest that the glacial reduction of the AL caused increased recirculation in the southwest Indian Ocean via the Agulhas reflection, where high evaporation led to salinification of surface waters (Simon et al., 2013). Figure $3 e$ and $3 i$ show that the increases in $\delta^{18} \mathrm{O}_{\mathrm{sw}}$ generally occurred during phases of low Agulhas Leakage, but not vice versa. It is therefore likely that the closure of the AL enhanced the salinification process by reducing the outflow of saline waters into the Atlantic, but did not drive it.

Model simulations of atmospheric circulation patterns above the Indian Ocean during the LGM suggest that the Indian Ocean Dipole was strengthened, potentially resembling an Indian ENSO pattern (DiNezio et al., 2018; Thirumalai et al., 2019). This would have led to drier conditions over the central, eastern, and north-western Indian Ocean (DiNezio et al., 2018; Thirumalai et al., 2019) and could have further enhanced the salinification of ITF and SEC waters. Although model results also suggest a potential freshening in the western Indian Ocean during the LGM (DiNezio et al., 2018), this is inconsistent with 
reconstructed salinity. Both western Indian Ocean core U1476 and Arabian Sea core TY93-929/P (Barker et al., 2003) show a comparable SST and $\delta^{18} \mathrm{O}_{\text {sw-ivc }}$ pattern to the Indian Ocean stacks, i.e. warming and salinification during glacial maxima (Figure S5), providing evidence that the western Indian Ocean evolved similarly to the rest of the basin. In sum, we suggest that the glacial salinification process in the surface Indian Ocean is a result of the abrupt reorganisation of land masses in the Indonesian archipelago driving a reduction in the ITF, and therefore a reduction in freshwater entering the SEC in the Indian Ocean. The occurrence of these events during times of generally weak Agulhas Leakage and high evaporation fostered the recirculation of water masses in the subtropical and tropical Indian Ocean gyre, and elevated salinity and temperature in surface waters at times of global glaciation.

The high salinity conditions in the glacial Indian Ocean can be traced along the AL system pathway and would therefore have influenced $A L$ waters after $A L$ resumption. Published $A L$ reconstructions show a resumption of the $\mathrm{AL}$ volume flow at the onset of deglaciations (Figure $3 \mathrm{i}$ ), and these leakage waters have been shown to be particularly salty (Marino et al., 2013). According to our results, the high salinity observed after AL resumption is likely sourced from the glacial Indian Ocean, whose salinification is highest just before deglaciation (Figure 3c). Climate model results under future climate change conditions suggest that a saltier AL directly impacts the global ocean circulation (Biastoch et al., 2009). However, little is known about the impact of a salty AL on the global overturning circulation during the onset of deglaciation. We therefore tested the influence of a salty $A L$ on the overturning circulation using a fully-coupled atmosphere-ocean global circulation model COSMOS (Zhang et al., 2013) for a deglacial freshwater event scenario with LGM parameters (see Methods 6). We first performed a classic North Atlantic hosing experiment (LGM_015) applying $0.15 \mathrm{~Sv}$ into the so-called Ruddiman Belt for 500 years to generate a weakened AMOC background under LGM conditions and thus mimic an early deglacial Heinrich stadial (see Zhang et al., 2013). To simulate an increased AL supplying saltier Indian Ocean water masses to the Atlantic, we then conducted two freshwater extraction experiments based on LGM_0.15 (persistently hosing in the North Atlantic) by additionally imposing constant high evaporation fluxes over the Agulhas plateau, equivalent to 0.05Sv (LGM_015 SA005) and 0.15Sv (LGM_015 SA01) saltwater input. After inducing salinification in the Agulhas plateau area, we see a complete AMOC recovery from around 7Sv to a peak of 25Sv in LGM_015 SA005 and 30Sv in LGM_015 SA01, with the onset of AMOC recovery occurring after $\sim 400$ years and $\sim 250$ years respectively (Figure 4 ). This suggests that a highly saline AL can have a direct impact on a Heinrich weakened AMOC, and can lead to an AMOC recovery even under a persistent freshwater input in the North Atlantic (which might be expected during deglaciation). Our results further suggest that the amount of salt available in the AL has an effect on the response time of the AMOC, as well as the recovery strength, with higher salinities leading to faster response times and stronger recovery. This underlines that the glacial salinification process in the tropical and subtropical Indian surface Ocean can have a direct influence not only on global overturning circulation, but also on the shape of deglaciations, depending on the amount of salt harvested throughout the glacial, and the speed of release through the AL.

\section{Declarations}


The authors would like to thank the members and crew of IODP expedition 361 for their hard work in collecting and providing the samples. This work was mainly funded through UK NERC grant NE/P000878/1 provided by S.B. J.W.B.R. received funding for this work from the European Research Council under the European Union's Horizon 2020 research and innovation program (grant agreement 805246). X.Z, and Y.S. were funded through the Natural Science Foundation of China (41988101, 42075047) and German Helmholtz Postdoc Program (PD-301).

\section{AUTHOR CONTRIBUTIONS}

S.N. collected, analysed and interpreted the data. S.N. wrote the paper, with support from all co-authors. J.W.B.R., M.B.A., and S.B. supported the collection, analysis, and interpretation of the data, and provided the grant. The samples were collected by I.R.H. and S.B. on IODP expedition 361. X.Z. and Y.S. conducted the GCM model simulations, B.dB. and H.T.M. conducted model runs and postprocessing of sea level and land/sea ratio reconstructions, and M.D.D. computed the data stacks. All authors provided comments on the final manuscript.

\section{References}

1. Sprintall, J., Wijffels, S. E., Molcard, R., \& Jaya, I. (2009). Direct estimates of the indonesian throughflow entering the indian ocean: 2004-2006. Journal of Geophysical Research: Oceans, 114(7). https://doi.org/10.1029/2008JC005257

2. Sengupta, D., Bharath Raj, G. N., \& Shenoi, S. S. C. (2006). Surface freshwater from Bay of Bengal runoff and Indonesian Throughflow in the tropical Indian Ocean. Geophysical Research Letters, 33(22). https://doi.org/10.1029/2006GL027573

3. Talley, L. D., \& Sprintall, J. (2005). Deep expression of the Indonesian Throughflow: Indonesian Intermediate Water in the South Equatorial Current. Journal of Geophysical Research, 110(C10), C10009. https://doi.org/10.1029/2004JC002826

4. Gordon, A. L., Ma, S., Olson, D. B., Hacker, P., Ffield, A., Talley, L. D., Wilson, D., \& Baringer, M. (1997). Advection and diffusion of Indonesian Throughflow Water within the Indian Ocean South Equatorial Current. Geophysical Research Letters, 24(21), 2573-2576. https://doi.org/10.1029/97GL01061@10.1002/(ISSN)1944-8007.WOCEEX1

5. Durgadoo, J. V., Rühs, S., Biastoch, A., \& Böning, C. W. B. (2017). Indian Ocean sources of Agulhas leakage. Journal of Geophysical Research: Oceans, 122(4), 3481-3499. https://doi.org/10.1002/2016JC012676

6. Beal, L. M., De Ruijter, W. P. M., Biastoch, A., Zahn, R., Cronin, M., Hermes, J., Lutjeharms, J., Quartly, G., Tozuka, T., Baker-Yeboah, S., Bornman, T., Cipollini, P., Dijkstra, H., Hall, I., Park, W., Peeters, F., Penven, P., Ridderinkhof, H., \& Zinke, J. (2011). On the role of the Agulhas system in ocean circulation and climate. In Nature (Vol. 472, Issue 7344, pp. 429-436). https://doi.org/10.1038/nature09983 
7. Biastoch, A., Böning, C. W., Schwarzkopf, F. U., \& Lutjeharms, J. R. E. (2009). Increase in Agulhas leakage due to poleward shift of Southern Hemisphere westerlies. Nature, 462(7272), 495-498. https://doi.org/10.1038/nature08519

8. de Boer, B., Stocchi, P., \& Van De Wal, R. S. W. (2014a). A fully coupled 3-D ice-sheet-sea-level model: Algorithm and applications. Geoscientific Model Development, 7(5), 2141-2156. https://doi.org/10.5194/gmd-7-2141-2014

9. van der Lubbe, H. J. L., Hall, I. R., Barker, S., Hemming, S. R., Baars, T. F., Starr, A., Just, J., Backeberg, B. C., \& Joordens, J. C. A. (2021). Indo-Pacific Walker circulation drove Pleistocene African aridification. Nature 598, 618-623. https://doi.org/10.1038/s41586-021-03896-3

10. Holbourn, A., Kuhnt, W., \& Xu, J. (2011). Indonesian Throughflow variability during the last 140 ka: The timor sea outflow. Geological Society Special Publication, 355, 283-303. https://doi.org/10.1144/SP355.14

11. Petrick, B., Martínez-García, A., Auer, G., Reuning, L., Auderset, A., Deik, H., Takayanagi, H., De Vleeschouwer, D., Iryu, Y., \& Haug, G. H. (2019). Glacial Indonesian Throughflow weakening across the Mid-Pleistocene Climatic Transition. Scientific Reports, 9(1), 16995. https://doi.org/10.1038/s41598-019-53382-0

12. Gordon, A. L., Susanto, R. D., \& Vranes, K. (2003). Cool Indonesian throughflow as a consequence of restricted surface layer flow. Nature, 425(6960), 824-828. https://doi.org/10.1038/nature02038

13. Sarr, A. C., Husson, L., Sepulchre, P., Pastier, A. M., Pedoja, K., Elliot, M., Arias-Ruiz, C., Solihuddin, T., Aribowo, S., \& Susilohadi. (2019). Subsiding sundaland. Geology, 47(2), 119-122. https://doi.org/10.1130/G45629.1

14. Peeters, F. J. C., Acheson, R., Brummer, G. J. A., De Ruijter, W. P. M., Schneider, R. R., Ganssen, G. M., Ufkes, E., \& Kroon, D. (2004). Vigorous exchange between the Indian and Atlantic oceans at the end of the past five glacial periods. Nature, 430(7000), 661-665. https://doi.org/10.1038/nature02785

15. Caley, T., Giraudeau, J., Malaizé, B., Rossignol, L., \& Pierre, C. (2012). Agulhas leakage as a key process in the modes of Quaternary climate changes. Proceedings of the National Academy of Sciences of the United States of America, 109(18), 6835-6839. https://doi.org/10.1073/pnas.1115545109

16. Bard, E., \& Rickaby, R. E. M. (2009). Migration of the subtropical front as a modulator of glacial climate. Nature, 460(7253), 380-383. https://doi.org/10.1038/nature08189

17. Simon, M. H., Arthur, K. L., Hall, I. R., Peeters, F. J. C., Loveday, B. R., Barker, S., Ziegler, M., \& Zahn, R. (2013). Millennial-scale Agulhas Current variability and its implications for salt-leakage through the Indian-Atlantic Ocean Gateway. Earth and Planetary Science Letters, 383, 101-112. https://doi.org/10.1016/j.epsl.2013.09.035

18. DiNezio, P. N., Tierney, J. E., Otto-Bliesner, B. L., Timmermann, A., Bhattacharya, T., Rosenbloom, N., \& Brady, E. (2018). Glacial changes in tropical climate amplified by the Indian Ocean. Science Advances, 4(12). https://doi.org/10.1126/sciadv.aat9658 
19. Thirumalai, K., DiNezio, P. N., Tierney, J. E., Puy, M., \& Mohtadi, M. (2019). An El Niño Mode in the Glacial Indian Ocean? Paleoceanography and Paleoclimatology, 34(8), 1316-1327.

https://doi.org/10.1029/2019PA003669

20. Barker, S., Greaves, M., \& Elderfield, H. (2003). A study of cleaning procedures used for foraminiferal Mg/Ca paleothermometry. Geochemistry, Geophysics, Geosystems, 4(9), n/a-n/a.

https://doi.org/10.1029/2003GC000559

21. Marino, G., Zahn, R., Ziegler, M., Purcell, C., Knorr, G., Hall, I. R., Ziveri, P., \& Elderfield, H. (2013).

Agulhas salt-leakage oscillations during abrupt climate changes of the Late Pleistocene.

Paleoceanography, 28(3), 599-606. https://doi.org/10.1002/palo.20038

22. Zhang, X., Lohmann, G., Knorr, G., \& Xu, X. (2013). Different ocean states and transient characteristics in Last Glacial Maximum simulations and implications for deglaciation. Climate of the Past, 9(5), 2319-2333. https://doi.org/10.5194/cp-9-2319-2013

\section{Figures}

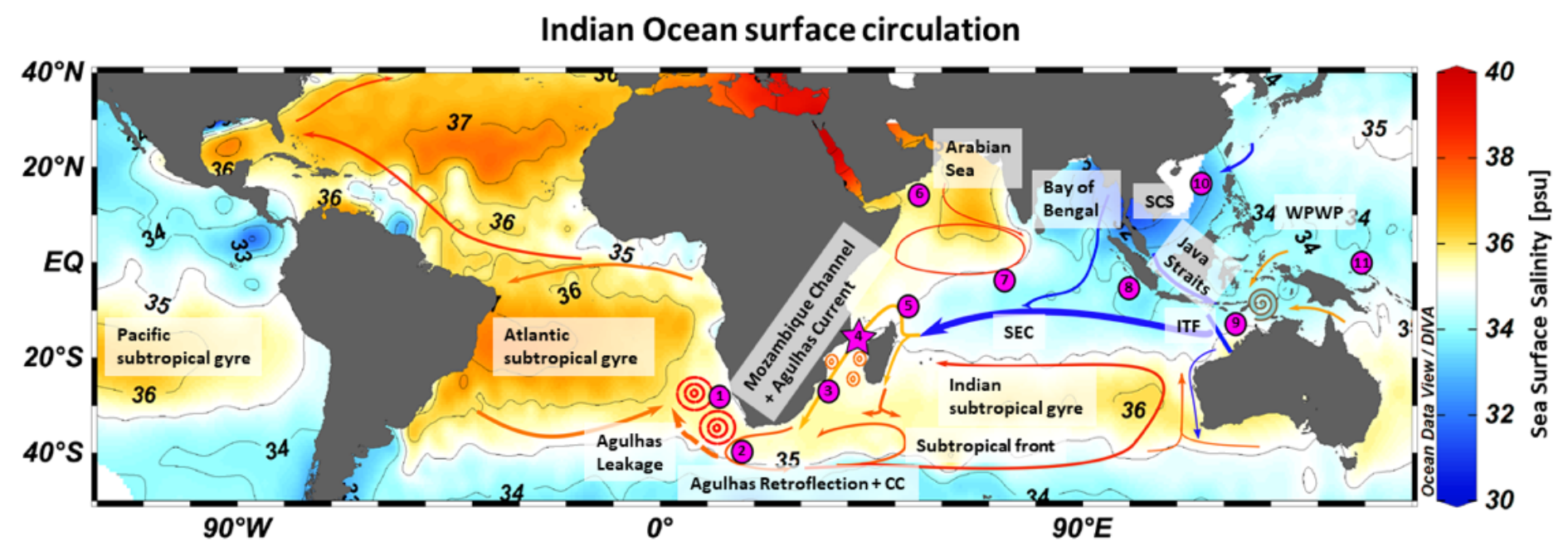

\section{Figure 1}

Modern ocean surface salinity distribution from GLODAP V2 (Lauvset et al., 2021) with key surface circulation patterns and study sites. Fresher and saltier water mass pathways are indicated with blue and orange arrows, respectively. The location of core site U1476 is plotted as a pink star 4 (this study); other core sites as numbered pink dots: 1 ODP1087 (Pierre et al., 2001), 2 Agulhas Bank Splice (MartinezMendez et al., 2010), 3 MD96-2048 (Caley et al., 2012), 5 WIND28K (Kiefer et al., 2006), 6 TY93929/P (Barker et al., 2003), 7 MD90-0963 (Rostek et al., 1997; Bassinot et al., 1994), 8 GeoB10038-4 (Mohtadi et al., 2010), 9 MD01-2378 (Xu et al., 2008; Zuraida et al., 2009), 10 ODP1146 (Herbert et al., 2010), 11 ODP806 (de Gardiel-Thoron et al., 2005). Sites $\bigcirc 2$ - 9 are used in our Indian Ocean data stacks. 


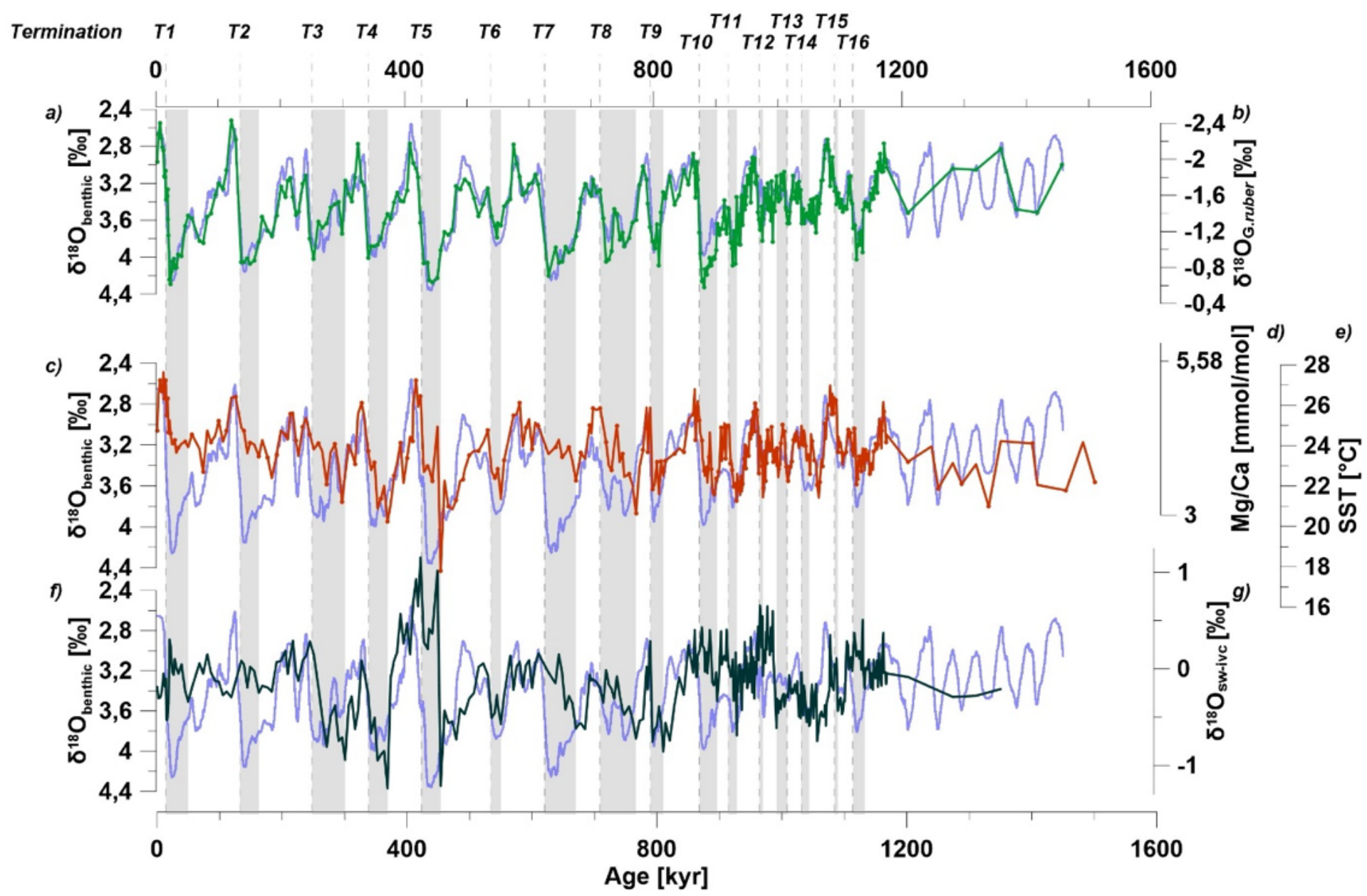

Figure 2

Comparison between benthic foraminifera $\delta 180$ (light blue lines in all panels) (van der Lubbe et al., 2021) and planktonic foraminifera-derived surface hydrography parameters from U1476 in the western Indian Ocean. (a) Benthic $\delta 180$ (van der Lubbe et al., 2021) and (b) planktonic $\delta 180$ carbonate ( $\delta 180 G$. ruber) (green line); (c) benthic $\delta 180$ as in (a), (d) planktonic $\mathrm{Mg} / \mathrm{Ca}$, and (e) calculated SSTs (red line); (f) benthic $\delta 180$ as in (a) and $(\mathrm{g})$ calculated ice-volume corrected $\delta 180$ sw for the surface ocean derived from the $1180 \mathrm{G}$. ruber and SST records (dark green). Timing of glacial cycle termination mid-points are indicated by dashed vertical lines and labelled T1 to T16. Note the increases in SST and 8180sw-ivc during glacial periods (grey shaded bars). 


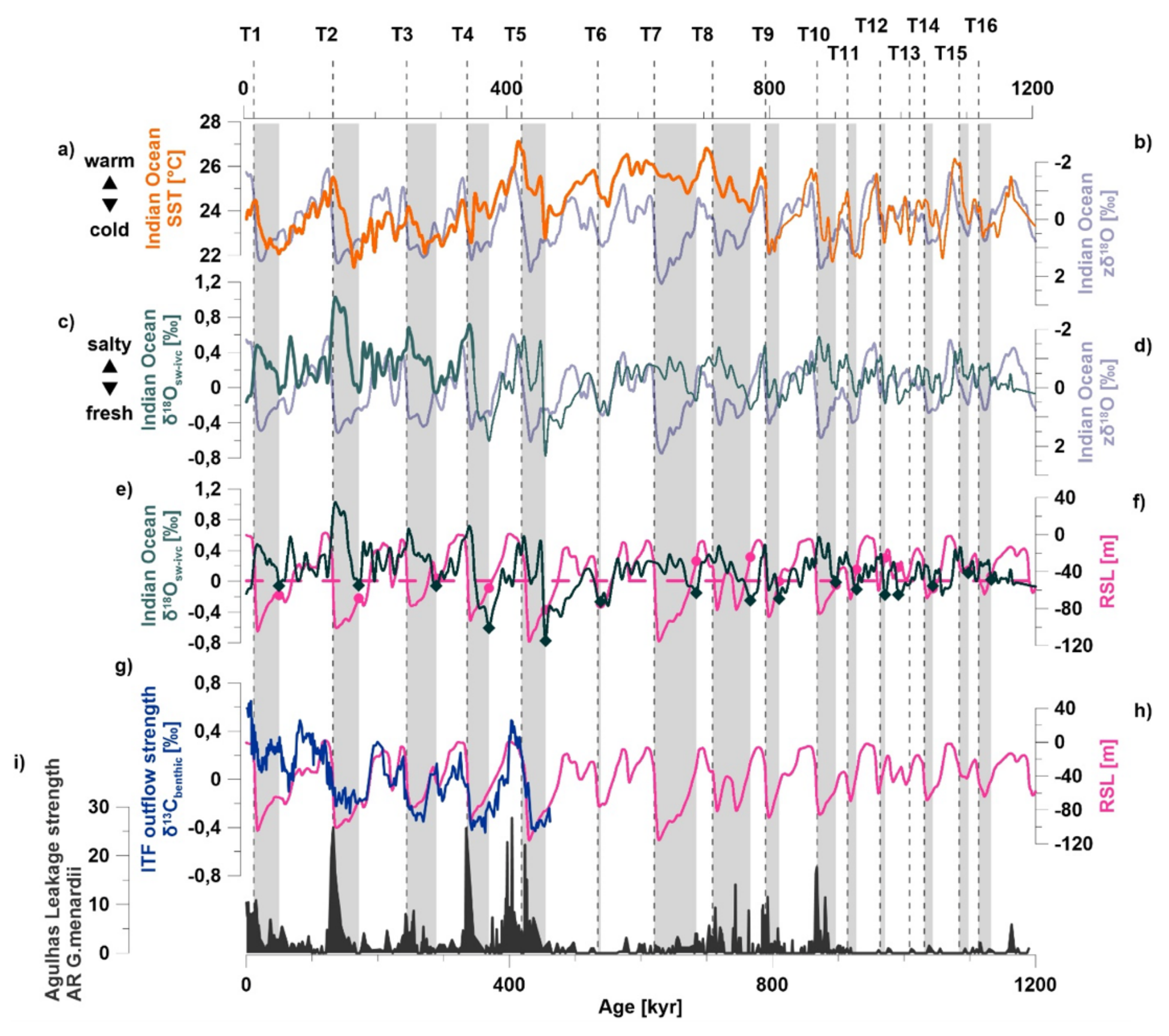

Figure 3

Regional records of Indian Ocean surface hydrography and its controls. (a) Sea surface temperature (SST) stack for the Indian Ocean (bold orange line), U1476 SST (thin orange line prior to $790 \mathrm{kyr}$ ), and (b) normalised stacked benthic $\delta 180$. (c) Ice volume-corrected $\delta 180$ sw stack for the Indian surface Ocean (bold green line), U1476 ice volume-corrected 8180 sw (thin green line prior to $345 \mathrm{kyr}$ ), and (d) normalised stacked benthic 8180 . (e) Indian Ocean stack ice volume-corrected 8180 sw (green line) for the surface Ocean, with the onset of $\delta 180$ sw-ivc increases indicated by green diamonds, and (f) relative sea level (de Boer et al., 2014) (pink line), with RSL-stands at onset of $\delta 180$ sw-ivc increases indicated by pink dots (e.g. pink dots mark RSL at the time of the green diamonds). The average RSL-stand that corresponds to increases $\delta 180$ sw-ivc is indicated with a horizontal dashed pink line. (g) Indonesian throughflow (ITF) outflow strength proxy (Holbourn et al., 2011) (blue line), and (h) relative sea level (de Boer et al., 2014) 
(pink line). (i) Agulhas Leakage strength proxy (Caley et al., 2012) (grey spikes). Intervals of rising stack$\delta 180$ sw-ivc prior to each glacial termination are indicated with vertical grey bars. Glacial terminations are labelled at the top, and indicated with dashed vertical lines.
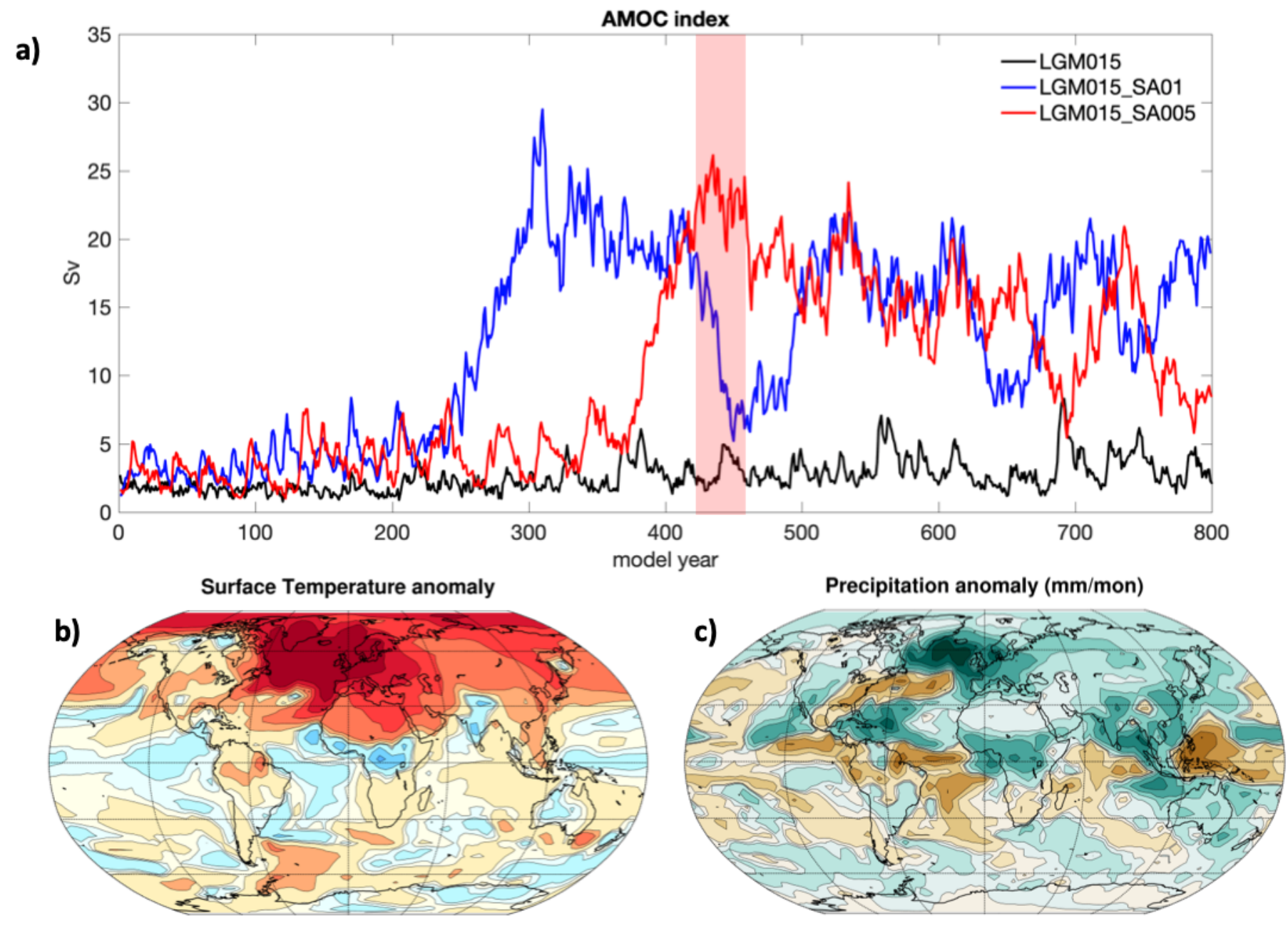

$\begin{array}{lllllllllllll}-5 & -3 & -2 & -1 & -0.5 & -0.1 & 0 & 0.1 & 0.5 & 1 & 2 & 3 & 5\end{array}$

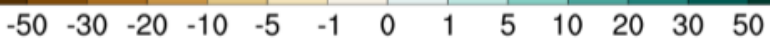

\section{Figure 4}

Simulated global responses to increased Agulhas Leakage salinity during North Atlantic freshwater perturbation events, representating deglacial onset conditions. a) AMOC index [Sv] for experiments with strong (LGM015_SA01, blue line) and weak (LGM015_SA005, red line) increase in Agulhas Leakage salinity, forced respectively by 0.1 and $0.05 S$ v evaporation anomalies over the Agulhas Plateau, compared to an experiment with no evaporation forcing shown in black (LGM015). The AMOC index is defined as the maximum of Atlantic meridional transport stream function north of $45^{\circ} \mathrm{N}$ at a water depth between $1000 \mathrm{~m}$ and $2500 \mathrm{~m} . \mathrm{b}$ ) and c) are responses of mean annual surface air temperature $\left({ }^{\circ} \mathrm{C}\right)$ and precipitation ( $\mathrm{mm} / \mathrm{mon}$ ) to an AMOC recovery state in LGM015_SA005 (i.e. anomalies between LGM015_SA005 and LGM015 for intervals indicated by red bar in panel a)).

\section{Supplementary Files}


This is a list of supplementary files associated with this preprint. Click to download.

- NuberetalSupplementNatureSubmission20211101.docx 